\title{
Influence of Soaking and Germination on the Iron, Phytate and Phenolic Contents of Maize Used for Complementary Feeding in Rural Tanzania
}

\author{
Fabian Mihafu ${ }^{1}$, Henry S. Laswai ${ }^{2}$, Peter Gichuhi ${ }^{1}$, Stewart Mwanyika ${ }^{2}$, \\ Adelia C. Bovell-Benjamin ${ }^{1, *}$ \\ ${ }^{1}$ Department of Food and Nutritional Sciences, Tuskegee University, Tuskegee, Alabama, USA \\ ${ }^{2}$ Department of Food Technology, Nutrition and Consumer Sciences, Sokoine University of Agriculture, Morogoro, Tanzania
}

\section{Email address:}

acbenjamin@mytu.tuskegee.edu (A. C. Bovell-Benjamin)

\section{To cite this article:}

Fabian Mihafu, Henry S. Laswai, Peter Gichuhi, Stewart Mwanyika, Adelia C. Bovell-Benjamin. Influence of Soaking and Germination on the Iron, Phytate and Phenolic Contents of Maize used for Complementary Feeding in Rural Tanzania. International Journal of Nutrition and Food Sciences. Vol. 6, No. 2, 2017, pp. 111-117. doi: 10.11648/j.ijnfs.20170602.18

Received: January 16, 2017; Accepted: February 4, 2017; Published: March 6, 2017

\begin{abstract}
Introduction: In developing countries including Tanzania, complementary foods fed to children are often carbohydrate-based and lack sufficient protein, energy, vitamins and micronutrients. Evidence suggests that the iron contained in foods such as cereals is not fully absorbed and will collect in the colon with the possibility of free radical generation and intestinal inflammation. Plant-based complementary foods have been reported to contain high levels of phytate and phenolic compounds, which impact on iron bioavailability. Phenolic compounds have an inhibitory effect on non-heme iron, making it unavailable for absorption in the intestinal tract. Traditional processing technologies (soaking and germination) are widely used in the Iringa District for making local 'brews'. Objective: The objective of the study was to determine the influence of soaking and germination on the iron, phytate and phenolic contents of maize used for complementary feeding in rural Tanzania. Materials and Methods: Maize grains collected from five Wards in the Iringa District were soaked in distilled water, drained and germinated at $0,36,48$ and 72 hours then processed into flour. Iron, phytate and phenolic contents were analyzed. Results: Iron content fluctuated with germination time, however a significant $(\mathrm{P}<0.05)$ increase was observed at the 72 -hour. Significant $(\mathrm{p}<0.05)$ reductions in the mean phytate contents of the samples (ranging from 8.3 to $34.1 \%$ reductions) were observed at the 72-hour germination time. Phenolic contents increased with germination time; there was a significant $(\mathrm{P}<$ 0.05) increase at the 72-hour germination time for the samples from all locations. Increases in phenolic contents in the soaked germinated maize ranged from 76.7 to $86.3 \%$. Conclusion: The processing technologies of soaking and germination commonly used in the Iringa District for making local 'brews' could be utilized to enhance the nutritional properties of complementary foods used by infants and young children. An awareness and education program to inform community members about transferring this technology and its usefulness to complementary feeding is recommended.
\end{abstract}

Keywords: Complementary Foods, Maize, Phytate, Polyphenols, Iron, Traditional Food Processing Methods

\section{Introduction}

Complementary feeding means giving other foods in addition to breast milk. The gradual shift from breast milk to solid foods is a transition period, which begins after an infant reaches six months of age and continues until the age of 24 months or more [1, 2]. According to the World Health Organization (WHO), complementary foods (CFs) are introduced to infants after the first six months of life to augment energy and nutrient intake to satisfy the infant's total nutritional requirements [2]. During the time they are consumed, CFs comprise a large proportion of the infant's diet and contribute a significant amount of the nutrients, which are necessary for growth and development [3]. As such, CFs must contain adequate quantities of the essential nutrients to complement milk. During complementary feeding period infants are said to be nutritionally vulnerable [1]. Infants who do not receive enough CFs may be stunted 
or malnourished or both [3].

During the first year of life, nutritional requirements are at their highest in the entire life cycle. Deficiency in energy or any of the essential nutrients could have catastrophic effects, some of which are long-lasting. In developing countries, CFs fed to children are often carbohydrate-based and lack sufficient protein, energy, vitamins and micronutrients. Nutritional problems associated with the use of starch staples in weaning foods are widely reported [4]. Traditional infant foods made of cereals or tubers are associated with bulkiness, high concentrations of fiber and inhibitors, which reduce their nutritional benefits [5-8].

Maize is the staple food for most families in many African countries including Tanzania. Maize flour serves as raw material for stiff porridges and weaning gruel [9]. Approximately $33 \%$ of Tanzanian children ages six to 59 months are iron and vitamin A deficient and $69 \%$ are anemic. Mosha et al. [4] have established that the majority of children in Tanzania are born with weights well above the recommended level of $2.5 \mathrm{~kg}$, and begin life in sound health. The researchers posited that growth starts to falter during and/or after the introduction of complementary foods.

Tanzania is dependent on cereal and root crop-based traditional weaning foods from maize, sorghum, millet, rice, cassava, potatoes, yams and plantains [10]. Mamiro et al. reported that among children aged three to 23 months in Kilosa District and Morogoro Region, Tanzania, plain maize porridge, finger millet, rice and peanut composite flour porridge, beans and sardines were the main complementary foods. Furthermore, older data from Tanzania standard (TZS 180: 1983) for processed cereal-based weaning foods [11] and Codex Alimentarius standards for cereal/milk based weaning/follow-up foods indicate that the majority of locally formulated complementary foods, as well as some commercial complementary foods used in Tanzania do not fulfill quality attributes, especially in terms of energy and micronutrient.

Iron is an essential mineral, which is needed for a number of highly complex processes such as oxidative metabolism, cellular proliferation and production of red blood cells [12]. It is also part of hemoglobin, which transports oxygen throughout the body [12]. Additionally, the immune system is dependent on iron for its efficient functioning [13]. Infancy is a time of rapid physical growth as well as physiological, immunological, and mental development. Iron must be judiciously regulated to promote optimal conditions that preserve the health of growing young children. Many factors are responsible for iron deficiency (ID) and iron deficiency anemia (IDA), however, one of the main causes of this nutritional problem in developing countries is the poor bioavailability of dietary iron [14]. In general, evidence suggests that the iron contained in foods such as cereals is not fully absorbed and will collect in the colon with the possibility of free radical generation and intestinal inflammation [15].

Plant-based complementary foods have been reported to contain high levels of phytate and phenolic compounds, which impact on iron bioavailability [16]. Prolonged consumption of maize porridge by infants and young children as their primary food puts them at high risk for developing ID and IDA [17]. In Tanzania, it is estimated that $50 \%$ of the cases of anemia are due to ID [7]. The low bioavailability of nutrients, arising from the presence of phytate, polyphenols, and oxalate, is a primary factor, which limits the quality of predominantly plant-based diets used for complementary feeding $[9,16]$.

Phytic acid also known as myo-inositol hexaphosphate or phytate when in the salt form is a naturally occurring compound found in many plant tissues [18]. Phytic acid is a good chelator of diatomic metals such as iron, zinc, magnesium and calcium [19]. Chelation of metal ions forms insoluble complexes in the gastrointestinal tract, which cannot be absorbed by the body [20]. Polyphenols are group of natural compounds with phenolic structural features. Polyphenols are the largest group of phytochemicals and are found mainly in plant-based foods [21, 22]. Polyphenols also have an inhibitory effect on non-heme iron, hence making it unavailable for absorption in the intestinal tract [12].

The high cost and inaccessibility of commercially formulated CFs put them out of reach to low-income Tanzanian households. Therefore, accessibility of ironfortified foods by people in rural areas is low. A simple soaking procedure appropriate for rural subsistence households has been developed; it can reportedly reduce the phytate content of unrefined maize flour by $50 \%$. Also, the Food and Agriculture Organization (FAO) [23] has encouraged the use of affordable processing techniques such as soaking, germination and fermentation to increase nutrient bioavailability in plant- based CFs. Traditional processing technologies (soaking and germination) have always been widely used in the Iringa District for making local 'brews' [24]. Soaking and germination is carried out at low cost without the use of any sophisticated and expensive equipment. Germination reduces phytate, thus improving nutritional properties of the food [25].

The need still exists to promote the use of traditional processing technologies to enhance availability of nutrients in complementary foods used by infants and young children living in resource-poor Tanzanian families [22]. Therefore, the objective of the study was to determine the influence of soaking and germination on the iron, phytate and phenolic contents of maize used for complementary feeding in rural Tanzania.

\section{Material and Methods}

\subsection{Research Setting}

The research was undertaken in the United Republic of Tanzania located in East Africa. Tanzania is bordered by Kenya and Uganda to the north; Rwanda, Burundi, and the Democratic Republic of the Congo to the west; and Zambia, Malawi, and Mozambique to the south. The country's eastern border is formed by the Indian Ocean. Iringa is one of 
Tanzania's 30 administrative regions (Figure 1). The regional capital is Iringa and the region is divided into four districts, namely: Iringa Urban District, Iringa District, Kilolo District and Mufindi District. According to Tanzania's 2012 census, Iringa District has 25 Wards and a population of 254,032.



Figure 1. Map of Tanzania, showing the administrative regions, Iringa Region is highlighted in green (Source: http://www.pesptz.org).

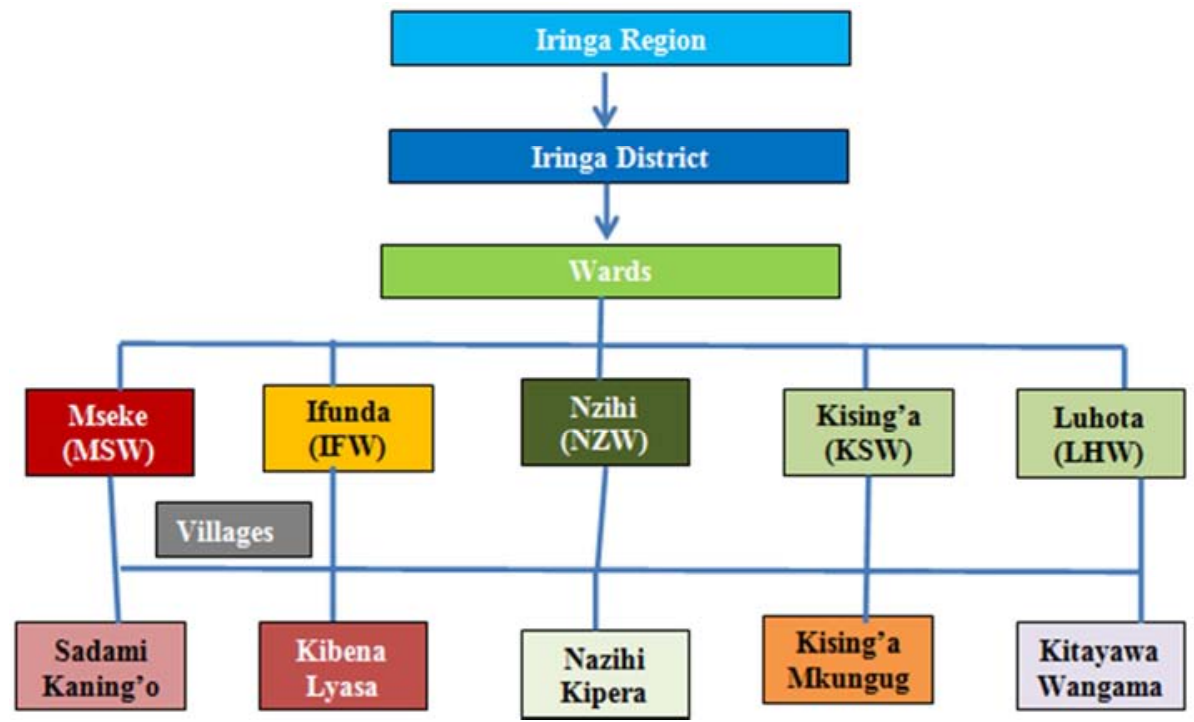

Figure 2. Schematic of sample collection locations.

\subsection{Sample Collection}

Maize (Zea mays) grains were collected from five Wards in Iringa District, Iringa Region, Tanzania for the study. Selection of the Wards was based on IDA prevalence that is, Wards with high prevalence of IDA, which had maize as the main diet were selected. Mseke, Ifunda, Nzihi, NduliKising'a and Luhota were the five Wards selected as they met the criteria. Two villages were chosen from each ward making a total of 10 villages used for sample collection (Figure 2). The samples (maize grains) were purchased from 
the Ward selling centers/warehouses. The collected maize grains were packed in bags/sacks and transported to the Food Science Laboratory at Sokoine University of Agriculture (SUA), Morogoro.

\subsection{Sample Preparation}

White maize kernels were sorted and winnowed manually to remove defective kernels, small sand particles, dust, stones and other extraneous materials. The cleaned maize kernels were soaked in distilled water for 24 hours with a ratio of $2 / 4$ $(\mathrm{w} / \mathrm{v})$. Well-made baskets were used for germinating the soaked maize; a moistened cotton cloth $(0.5 \mathrm{~m} \mathrm{x} 0.5 \mathrm{~m})$ was placed inside the basket and folded to cover the base circumference. Soaked maize grains were spread on the cloth and covered by another cloth of the same length on top.

The baskets were arranged along a well cleaned channel to allow draining. The maize grains were germinated at 0,36 , 48 and 72 hours. Sodium chloride (table salt) solution $(3 \%$ $\mathrm{w} / \mathrm{v}$ ) was spread over the germinating maize to control mold growth. The baskets were covered with a black cloth to protect the photosynthetic light while maintaining warmth to facilitate sprouting. The germinated maize was spread on wire mesh and dried in Advantec Forced Convection Oven FC-612 (Toyo Seisakusho CO, Ltd) at $50^{\circ} \mathrm{C}$ for 36 hours. The samples were ground in a hammer mill (Christy Hunt Engineering Ltd, Coldhester Essex CO6 2EP, England) into flour. The maize flour was packed in Ziploc ${ }^{\circledR}$ bags and sealed with a Plastic Film Sealer Machine (PFS-250). The sealed samples were kept in a freezer at $-18^{\circ} \mathrm{C}$ until further analysis.

\subsection{Chemical Analysis}

\section{Total iron determination}

Total iron was determined following the procedures described by Tee et al. [26]. The samples ( $5 \mathrm{~g}$ ) were measured and blended. After homogenization, the samples were dried in an air oven at $105^{\circ} \mathrm{C}$ for 3 hours until it ceased to smoke. The charred sample was ashed in a muffle furnace (Carbonite Aston Lane Hope, Shelfield, England) at $550^{\circ} \mathrm{C}$. The ash was treated with concentrated hydrochloric acid $(\mathrm{HCl})$, transferred to a $50 \mathrm{~mL}$ volumetric flask and diluted to the mark. The aliquot of the ash solution was used for determination of iron by Atomic Absorption Spectrophotometer (UNICAM 919 AA Spectrophotometer) at $248.3 \mathrm{~nm}$.

\section{Phytic acid determination}

Phytic acid was determined following the method described by Wheeler and Ferrel [27] with minor modifications. A standard solution was prepared using ferric nitrate $\mathrm{Fe}\left(\mathrm{NO}_{3}\right)_{3}$. The color was read immediately at $480 \mathrm{~nm}$ within 1 minute and the standard curve was drawn.

\section{Phenolic compounds determination}

Phenolic compounds/polyphenols were determined following the procedures described by Ragazzi and Veronese [28]. Gallic acid $(0.5 \mathrm{mg} / \mathrm{mL})$ was prepared in $80 \%$ methanol for standard curve. Five serial dilutions were made, $100 \mu \mathrm{L}$
Folin-Ciocalteus phenol reagent (Southend-On-Sea Pharmacos Ltd., Essex, England) was added and mixed. Within 3 seconds and 8 minutes, $300 \mu \mathrm{L}$ sodium carbonate (E-Merck-D-600 Darmstadt, Germany) were added and mixed. The absorbance was read at $765 \mathrm{~nm}$ (Jenway 6405 UV/Vis Spectrophotometer, Japan).

\section{Statistical Analysis}

The experiment was performed in duplicate. The mean and standard deviation of means were calculated. The data were analyzed by one-way analysis of variance (ANOVA). Duncan's multiple range test was used to separate means. Significance was accepted at probability $\mathrm{p}<0.05$. Data were analyzed with Statistical Analysis System (SAS) 9.1

\section{Results and Discussion}

Total iron

Iron content fluctuated with germination time for the maize obtained from all Wards (Table 1). The samples from LHW showed a significant decrease in iron content at the 36 and 48-hour compared to the control with 0 -hour germination time, but were similar to the control at the 72-hour (Table 1). Increases in iron content in the four other Wards ranged from 2.4 to $12.8 \%$. The beneficial effect of germination on iron may probably be attributed to the decrease in phytate content as a result of soaking and germination. It was also observed that the maize obtained from Kising'a ward (KSW) had low iron content $(0.91 \pm 0.6 \mathrm{mg}$ to $1.09 \pm 0.8 \mathrm{mg})$ as compared to those obtained from the other Wards (Table 1). The variation of iron content in the given locations, may be attributed to other factors such as soil and fertilizer, however the reasons for these variations are unclear. Soaking and germination showed a positive impact on iron solubility as iron increased significantly $(\mathrm{P}<0.05)$ from $1.4 \mathrm{mg} / 100 \mathrm{~g}$ at the 0 -hour to 2.0 $\mathrm{mg} / 100 \mathrm{~g}$ at the 72 -hour (Table $2 \mathrm{a}$ ).

Table 1. Interactive effect of location and germination on total iron content (mg/lo0 g) of soaked and germinated maize.

\begin{tabular}{lllll}
\hline Location & \multicolumn{4}{l}{ Germination time (h) } \\
\hline & $\mathbf{0}$ & $\mathbf{3 6}$ & $\mathbf{4 8}$ & $\mathbf{7 2}$ \\
\hline IFW & $1.2 \pm 0.2^{\mathrm{b}}$ & $1.1 \pm 0.01^{\mathrm{c}}$ & $1.2 \pm 0.4^{\mathrm{b}}$ & $1.3 \pm 0.7^{\mathrm{a}}$ \\
KSW & $0.9 \pm 0.2^{\mathrm{b}}$ & $0.9 \pm 0.01^{\mathrm{b}}$ & $0.9 \pm 0.6^{\mathrm{b}}$ & $1.1 \pm 0.8^{\mathrm{a}}$ \\
LHW & $1.2 \pm 0.1^{\mathrm{a}}$ & $1.1 \pm 0.2^{\mathrm{b}}$ & $1.1 \pm 0.5^{\mathrm{b}}$ & $1.2 \pm 0.6^{\mathrm{a}}$ \\
MSW & $1.2 \pm 0.1^{\mathrm{b}}$ & $1.2 \pm 0.1^{\mathrm{b}}$ & $1.2 \pm 0.8^{\mathrm{b}}$ & $1.3 \pm 0.5^{\mathrm{a}}$ \\
NZW & $1.2 \pm 0.1^{\mathrm{b}}$ & $1.2 \pm 0.3^{\mathrm{b}}$ & $1.2 \pm 0.1^{\mathrm{b}}$ & $1.3 \pm 0.8^{\mathrm{a}}$ \\
\hline
\end{tabular}

Values are means \pm SD (standard deviation) of duplicate determination. Means with the same superscripts within the same row are not significantly different $(\mathrm{P}<0.05)$. IFW- Ifunda Ward; KSW - Kising'a Ward; LHW Luhota Ward; MSW - Mseke Ward; NZW - Nzihi Ward.

Table 2a. Effect of soaking and germination on iron content (mg/100 g) of soaked and germinated maize.

\begin{tabular}{lllll}
\hline Germination time (h) & $\mathbf{0}$ & $\mathbf{3 6}$ & $\mathbf{4 8}$ & $\mathbf{7 2}$ \\
\hline Total iron $(\mathrm{mg} / 100 \mathrm{~g})$ & $1.4^{\mathrm{a}}$ & $1.5^{\mathrm{b}}$ & $1.8^{\mathrm{c}}$ & $2.1^{\mathrm{d}}$ \\
SEM & 0.14 & & & \\
P-value & 0.0001 & & & \\
\hline
\end{tabular}

Phytates

There was a significant $(\mathrm{P}<0.05)$ decrease of phytates in 
soaked and germinated maize from all Wards (Table 2b). In general, much of the phytates were efficiently removed at the 72-hour germination time (Table 2). Significant $(\mathrm{P}<0.05)$ reduction in phytate from $41.7 \pm 4.5 \mathrm{mg} / 100 \mathrm{~g}$ at 0 hour to $27.5 \pm 0.5 \mathrm{mg} / 100 \mathrm{~g}$ at the 72-hour was recorded in one Ward, that is a $34.1 \%$ reduction. In this study, all the maize had equal soaking time. Phytate is water soluble; therefore soaking the grains in water resulted in its passive diffusion [29]. A significant phytate reduction can be realized by discarding the soak water [29]. As seen in the current study, soaking usually forms an integral part of the germination process. Hotz and Gibson [30] have developed a simple soaking procedure appropriate for rural subsistence households, which can reportedly reduce the phytate content of unrefined maize flour by $50 \%$. In the current study, phytate content of soaked and germinated maize flour was reduced by $8.3 \%$ in IFW to $34.1 \%$ in $\mathrm{KSW}$.

Generally, germination improves the nutritional quality of foods by increasing their nutrient content and digestibility [31]. Several studies reported on the decrease of phytates in soaked and germinated maize. For example, Sokrab et al. [32], observed a decrease in phytate content in high and low phytate corn genotypes soaked for 12 hours and germinated for 2,4 and 6 days at room temperature of $32^{\circ} \mathrm{C}$ to $38^{\circ} \mathrm{C}$. Also, Egli et al, [33] reported a decrease of phytate content from $1.2 \mathrm{mg} / 100 \mathrm{~g}$ to $0.8 \mathrm{mg} / 100 \mathrm{~g}$ in whole maize grain soaked for 16 hours and germinated for 24,48 and 72 hours.

Table 2b. Effect of location and germination on phytate content ( $\mathrm{mg} / 100 \mathrm{~g}$ ) of soaked and germinated maize grains.

\begin{tabular}{|c|c|c|c|c|}
\hline \multirow[t]{2}{*}{ Location } & \multicolumn{4}{|c|}{ Germination time (h) } \\
\hline & $\mathbf{0}$ & 36 & 48 & 72 \\
\hline IFW & $42.0 \pm 1.2^{\mathrm{a}}$ & $40.6 \pm 0.01^{\mathrm{b}}$ & $39.7 \pm 0.5^{b}$ & $38.5 \pm 0.1^{\mathrm{c}}$ \\
\hline KSW & $41.7 \pm 4.5^{\mathrm{a}}$ & $40.6 \pm 4.3^{b}$ & $39.0 \pm 1.5^{b}$ & $27.5 \pm 0.5^{\mathrm{c}}$ \\
\hline LHW & $45.3 \pm 1.2^{\mathrm{a}}$ & $41.1 \pm 1.6^{\mathrm{b}}$ & $35.7 \pm 2.2^{\mathrm{c}}$ & $34.6 \pm 3.8^{\mathrm{d}}$ \\
\hline MSW & $41.4 \pm 6.4^{\mathrm{a}}$ & $38.1 \pm 0.3^{b}$ & $37.7 \pm 0.02^{\mathrm{b}}$ & $36.9 \pm 0.2^{\mathrm{c}}$ \\
\hline NZW & $28.0 \pm 1.7^{\mathrm{a}}$ & $26.6 \pm 0.4^{b}$ & $26.3 \pm 0.4^{\mathrm{b}}$ & $24.9 \pm 0.9^{c}$ \\
\hline
\end{tabular}

Values are means \pm SD (standard deviation) of duplicate determination. Means with the same superscripts within the same row are not significantly different $(\mathrm{P}<0.05)$. IFW- Ifunda Ward; KSW - Kising'a Ward; LHW Luhota Ward; MSW - Mseke Ward; NZW - Nzihi Ward

The reduction in the phytate content during germination could be attributed to an increase in the activity of endogenous phytase, which hydrolyzes phytic acid in maize $[34,35]$. It has been generally accepted that during germination, de novo synthesis and activation of endogenous phytases with concurrent reduction in phytate content occurs in cereals [31]. Phytins are broken down by endogenous phytase enzymes, releasing their $\mathrm{P}$, myo-inositol and mineral contents for use by the growing seedling [36]. The extent of the phytate hydrolysis varies with the species and variety, the stage of germination, $\mathrm{pH}$, moisture content, temperature, solubility of phytate and the presence of certain inhibitors [33]. Another beneficial effect of germination of cereals is the increased activity of $\alpha$-Amylase. $\alpha$-Amylase hydrolyzes amylase and amylopectin to dextrins and maltose, this reduces the viscosity of thick cereal porridges without dilution with water while concurrently improving their energy and nutrient densities [37].

Abd El Rahaman et al. [38] and Vadivel et al. [39] revealed that the decrease in the level of phytic acid during soaking may be attributed to leaching out of the acid into water. Also, Suma and Urooj [25] have reported drastic reductions, approximately $50 \%$ of phytate in pearl millet upon germination. Therefore, soaking and germination can reduce significantly the levels of phytates in maize-based complementary foods hence increasing nutrient bioavailability, particularly iron. In the present study, significant $(\mathrm{P}<0.05)$ phytate reductions in soaked and germinated maize ranged from 10.9 to $34.1 \%$ at the 72 -hour.

Phenolic/polyphenolic compounds

The polyphenolic compounds was significantly $(\mathrm{P}<0.05)$ increased at the 72-hour for the maize obtained in all Wards (Table 3). Maize from all the Wards except IFW showed significant $(\mathrm{P}<0.05)$ decreases in phenolic compounds from the 0 to 36-hour and increased thereafter. Tordorvi et al. [40] reported a similar situation where maize seeds in germination process initially showed no change in the concentration of phenolics, followed by a small decrease, then an overall large increase. It was also observed that the maize obtained from MSW Ward produced higher amounts of phenolic compounds $(1268.38 \mathrm{mg} / 100 \mathrm{~g})$ at the 72 -hour, an $86 \%$ increase compared to the other samples (Table 3 ). In general, the increases in phenolic contents ranged from 76.7 to $86.3 \%$. The lowest overall increase in phenolics at the 72-hour was seen in maize from the NZW location. The increase in polyphenols could be attributed to solubilization of condensed tannins when seeds are soaked in water and its movement to the outer layer during seed germination.

Table 3. Effect of germination on phenolic compound content (mgGAE/100 g) of soaked and germinated maize grains.

\begin{tabular}{lllll}
\hline Location & \multicolumn{5}{l}{ Germination time (h) } & & \\
\hline & $\mathbf{0}$ & $\mathbf{3 6}$ & $\mathbf{4 8}$ & $\mathbf{7 2}$ \\
\hline IFW & $143.6^{\mathrm{d}}$ & $174.5^{\mathrm{c}}$ & $329.3^{\mathrm{b}}$ & $789.9^{\mathrm{a}}$ \\
KSW & $178.7^{\mathrm{b}}$ & $145.0^{\mathrm{d}}$ & $176.5^{\mathrm{c}}$ & $827.4^{\mathrm{a}}$ \\
LHW & $155.8^{\mathrm{c}}$ & $149.1^{\mathrm{d}}$ & $197.4^{\mathrm{b}}$ & $839.9^{\mathrm{a}}$ \\
MSW & $174.4^{\mathrm{c}}$ & $169.3^{\mathrm{d}}$ & $848.2^{\mathrm{b}}$ & $1268.4^{\mathrm{a}}$ \\
NZW & $177.4^{\mathrm{b}}$ & $150.9^{\mathrm{d}}$ & $163.3^{\mathrm{c}}$ & $760.5^{\mathrm{a}}$ \\
\hline
\end{tabular}

Values are means \pm SD (standard deviation) of duplicate determination. Means with the same superscripts within the same row are not significantly different $(\mathrm{P}<0.05)$. IFW- Ifunda Ward; KSW - Kising'a Ward; LHW Luhota Ward; MSW - Mseke Ward; NZW - Nzihi Ward.

The variation in the overall phenolic compounds among the Wards might be due to fact that storage conditions and drying methods used by the farmers or households differed. Also, the stage of maturation of the maize could have differed from place to place. However our findings are consistent with those reported by Sokrab et al. [32] who observed an increase in polyphenols of high and low phytates corn genotypes soaked for 12 hours and germinated for 2, 4 and 6 days. The beneficial effect of phenolic compounds has been reported by some studies as being protective of infants and young children from food allergies and inflammation. 
For example, Yao et al. [41] reported that phenolic compounds such as flavonoids have anticancer, antioxidant, anti-inflammatory anti-allergic, cholesterol lowering and anti-ulcerogenic properties. Ardekan et al., [42], reported that consumption of foods with high phenolic content is correlated with reduced cardiovascular diseases, type II diabetes, inflammation and cancer.

In sum, the soaked and germinated maize from MSW had the highest increase in phenolic content $(83.6 \%$ ), a $10.9 \%$ reduction in phytate and an $11.4 \%$ increase in iron content. Soaked and germinated maize from IFW had an $82 \%$ increase in phenolic content, $8.3 \%$ reduction in phytate and $2.4 \%$ increase in iron content. In terms of phenolic concentrations, the soaked and germinated maize from NZW had a $76.7 \%$ increase, $11.1 \%$ reduction in phytate and $9.0 \%$ increase in iron. A $78.4 \%$ increase in phenolic compounds, $34.1 \%$ reduction in phytate and $12.8 \%$ increase in iron content were observed in soaked and germinated maize from KSW. For the soaked and germinated maize from LHW, there was a $4.1 \%$ reduction in iron content, $81.5 \%$ increase in phenolic content and $23.6 \%$ reduction in phytate at the 72 hour germination.

\section{Conclusion}

The present study showed that mostly iron content increased at the 72-hour germination time for the maize. The findings also revealed significant reductions of phytate in soaked and germinated maize. Such reductions may have contributed to the increases in iron content observed. On the other hand, polyphenol contents increased with germination time, most significantly at the 72-hour. It is clear that the traditional processing technologies of soaking and germination, which are commonly used in the Iringa District, Tanzania for making local 'brews' could be utilized to enhance the nutritional properties of complementary foods used by infants and young children living in the resourcepoor communities studied. The commonly used technology is low cost and does not require any sophisticated and expensive equipment. An awareness and education program to inform community members about transferring this technology and its usefulness to complementary feeding is recommended.

\section{Acknowledgements}

The authors acknowledge the United States Agency for International Development (USAID)/Innovative Agricultural Research Initiative (iAGRI) for providing the funds to carry out this research.

\section{References}

[1] Muhimbula, H. S and Zacharia, A. I. Persistent child malnutrition in Tanzania: Risks associated with traditional complementary foods. Asian J Food Sci. (2010) 4: 679-692.
[2] INFACT Canada. Complementary feeding: A solid start. Spring/Summer 2005 Newsletters. (2005). Available at: http://www.infactcanada.ca/newsletter; accessed 01/09/2016.

[3] Yeung DL. 2016. Iron and micronutrients: Complementary food fortification. Available at:

http://archive.unu.edu/unupress/food/V192e/ch11.htm; accessed 01/09/2016.

[4] Mosha TCE, Laswai HS, Tetens I. Nutritional composition and micronutrient status of home-made and commercial weaning foods consumed in Tanzania. Plant Foods Hum Nutr. (2000) 55: 185-205.

[5] Michaelsen KF, Friish H. Complementary feeding: a global perspective. Nutrition (1998) 14: 763-766.

[6] Urga K., Narasimha HV. Traditional sour dough bread (Difo Dabbo) making: I. Effects on phytic acid destruction. Ethiop J Health Dev. (1998) 12:175-181.

[7] Hurrell RF. Influence of vegetable protein sources on trace element and mineral bioavailability J Nutr. (2003) 133: 2973S-29777S.

[8] Mbithi-Mwikya S., van Camp J., Mamiro PRS, Ooghe W., Kolsteren P., Huyghebaert A. Evaluation of the nutritional characteristics of a finger millet based complementary food. $\mathrm{J}$ Agric Food Chem 50: 3030-3036.

[9] Nuss E. T and Tanumihardjo S. A.). Quality protein maize for Africa: Closing the protein inadequacy gap in vulnerable populations. Adv. Nutr. (2011) 2: 217-224.

[10] Mamiro PR, Van Camp J, Roberfroid D, Kolsteren P, Huyghebaert A. Prevalence of malnutrition and anaemia among infants aged 4-12 months in Kilosa district-rural Tanzania. Meded Rijksuniv Gent Fak Landbouwkd Toegep Biol Wet. (2001) 66: 69-73.

[11] TBS (Tanzania Bureau of Standards). Tanzania standard for processed cereal based weaning foods - Specification. Dar es Salaam: Tanzania Bureau of Standards (1983).

[12] Tanzania Demographic Health Survey 2010. Available at: www. dhsprogram.com; accessed 01/14/2016.

[13] Geissler C., Singh M. Iron, meat and health. Nutrients (2011) 2: 283-316.

[14] Hurrell R., Egli I. Iron bioavailability and dietary reference values. Am J Clin Nutr. (2010) 91(suppl): 1461S-1467S

[15] Friel J., Qasem W., Hossain Z., Jorgensen. Iron and complementary feeding of breast-fed infants. The FASEB J (2014) 28 (suppl.): 247.3.

[16] Gibson R. S, Bailey K. B, Gibbs M., Ferguson EL. A review of phytate, iron, zinc, and calcium concentrations in plantbased complementary foods used in low-income countries and implications for bioavailability. Food Nutr Bull. (2010) 31: S134-S146.

[17] Hotz, C., Gibson RS. Traditional food-processing and preparation practices to enhance the bioavailability of micronutrients in plant-based diets. J Nutr. (2007) 137: 10971100 .

[18] Tako E. Hoekenga OA, Kochian LV, Glahn RP. High bioavailability iron maize (Zea mays L) developed through molecular breeding provides more absorbable in vitro (Caco-2 model) and in vivo (Gallus gallus). J Nutr. (2013) 12: 3. 
[19] Azeke MA, Egielewa SJ, Eigbogbo MU, Ihjmire IG. Effect of germination on the phytase activity, phytate and total phosphorous content of rice (Oryza sativa), maize (Zea mays), sorghum (Sorghum bicolor) and Wheat (Triticum aestivum). J Food Sci Technol. (2010) 48: 724-729.

[20] Zamzam RK, Zito CA, Hunt JR. Inhibitory effects of dietary calcium on the initial uptake and subsequent retention of hem and no-heme iron in humans: comparisons using an intestinal lavage method. Am J Clin Nutr. (2005) 85: 589-97.

[21] Tsao R. Chemistry and Biochemistry of Dietary Polyphenols. Nutrients (2010) 2: 1231-1246.

[22] Steinmacher J., Pohlandt F., Bode H., Sander S., Kron M., Franz AR. Randomized trial of early versus late enteral iron supplementation in infants with a birth weight of less than 1301grams: Neurocognitive development at 5.3 years corrected age. Pediatrics (2007) 120.

[23] Gopper SS. Advanced Nutrition and Human Metabolism, $5^{\text {th }}$ edition. Wadsworth, Cengage Learning (2009).

[24] Mihafu F. O Optimizing Traditional Home Processing Technologies to Increase Nutrient Bioavailability of Complementary Foods in Rural Tanzania. MS Thesis, Tuskegee University Library, Tuskegee, Alabama, USA (2014).

[25] Suma PF, Urooj A. Influence of germination on bioaccessible iron and calcium in pearl millet (Pennisetum typhoideum). J Food Sci Technol (2014) 51: 976-981.

[26] Tee ES, Choo KS, Shahid SM. Determination of iron in foods by the atomic absorption spectrophotometric and colorimetric methods. PERTANIA (1989) 12: 313-322.

[27] Wheeler EL, Ferrel RE. A Method for phytic acid determination in wheat and wheat fractions. J. Cereal Chem (1971) 48: 312-320.

[28] Ragazzi E., Veronese G. Quantitative analysis of phenolic compounds after thin-layer chromatographic separation. J Chromatogr (1973) 77: 369-375.

[29] Affify AMR, El-Beltagi HS, Abd El-Salam SA, Omran AA. Bioavailability of iron, zinc, phytate and phytase activity during soaking and germination of white sorghum varieties. PLoS One (2011) 6: e25512.

[30] Hotz C, Gibson RS. Assessment of home-based processing methods to reduce phytate content and phytate/zinc molar ratios of white maize (Zea mays). J Agric Food Chem (2001) 49: 692-698.

[31] Luo W-H., Jin X-X, Wang Q, He Y-J. Effects of germination on iron, zinc, calcium, manganese, and copper availability from cereals and legumes. CyTA - J Food (2014) 12: 22-26.

[32] Sokrab AM, Ahmed IAM, Babiker EE. Effect of germination on antinutritional factors total and extractable minerals of high and low phytate corn (Zea mays L) genotypes. J Saudi Soc Agric Sci (2012) 11: 123-128.

[33] Egli I, Davidsson L, Juillerat M-A, Barclay D, Hurrell R. The influence of soaking and germination on the phytase activity and phytic acid content of grains and seeds potentially useful for complementary feeding. J Food Sci (2002) 67: 3484-3488.

[34] Awada, S. H et al., (2005). Antinutritional factors content and availability of protein, starch and mineral of maize (Zea mays $L$ ) and Lentil (Lens culinaris) as influenced by domestic processing. Food Technol (2005) 3: 523-528.

[35] Pawar VD, Machewad GM. Changes in availability of iron in barely during malting. J Food Sci Technol (2006) 43: 28-29.

[36] Raboy V. The biochemistry and genetics of phytic acid synthesis. In: Morre D, Boss W, Loewus F, editors. Inositol metabolism in plants. New York: Wiley-Liss; (1990) pp. 5576.

[37] Gibson RS, Yeudall F, Drost N, Mitimuni B, Cullinan T. Dietary interventions to prevent zinc deficiency. Am J Clin Nutr (1998) 68 (2 Suppl): 484S-487S.

[38] Abd El Rahaman SM, El Maki HB, Idris WH, Hassan AB, Babiker EE, Tinay AH. Anti-nutritional factors content and hydrochloric acid extractability of minerals in pearl millet cultivars as affected by germination. Internat J Food Sci Nutr. (2007) 58: 6-17.

[39] Vadivel V., Stuetz W., Scherbaum V. Total free phenolic content and health relevant functionality of Indian wild legume grains; effects of indigenous processing methods. J. Food Comp Anal. (2011) 24: 935-943.

[40] Todorovi M., Simi A., Sredojevi S., Todorovi M., Dukanovi L., Radenovi A. Studies on the relationship between the content of total phenolics in exudates and germination ability of maize seed during accelerated aging. Available at: http://www.seedtest.org/; accessed 01/14/2016

[41] Yao LH, Jiang YM, Shi J, Tomas-Barberan FA, Datta N., Singanusong R., Chen SS. Flavonoids in food and their health benefits. Plant Foods Hum Nutr. (2004) 59: 113-122.

[42] Ardekani MRS, Hajimahmoodi M., Oveisi MR, Sadeghi N, Jannat B., Ranjbar AM, Gholam N., Moridi T. Comparative antioxidant activity and total flavonoid content of Persian pomegranate. Iranian J. Pharm. Res (2011) 10: 519-524. 